\title{
Metastatic Spindle Cell Variant of Squamous Cell Carcinoma of Nasal Cavities Initially Presenting as Cervical Lymphadenopathy: A Case Report
}

\author{
Khatri Kishore ${ }^{1}$, Kumar Ankur²*, Sharma Mayank ${ }^{3}$ \\ ${ }^{1}$ Assistant Professor, Department of Pathology, Dr. S. N. Medical College, Jodhpur, Rajasthan, India. \\ ${ }^{2}$ Senior Resident, Department of Pathology, Bhagwan Mahavir Hospital, Sumerpur Pali, Rajasthan, India. \\ ${ }^{3}$ Senior Resident, Department of Pathology, Govt. Medical College, Kota, Rajasthan, India.
}

\begin{abstract}
We describe a case of spindle cell variant of squamous cell carcinoma presenting with cervical lymph-adenopathy. Patient had been suffering from bilateral nasal bleeding since 9 months and found to have bilateral nasal mass, which was polypoid and bleed on touch. FNAC from cervical node were initially diagnosed as spindle cell variant of squamous cell carcinoma. Punch biopsy of nasal mass also confirmed the same diagnosis. The possibility of metastatic spindle cell squamous carcinoma should always be considered in adults with enlarged cervical lymph nodes that show spindle cells with conventional squamous cell carcinoma. Immunophenotypic studies easily resolve this diagnostic dilemma between squamous and spindle cell mesenchymal neoplasms.
\end{abstract}

\section{ITRODUCTION}

Squamous cell carcinoma is the most common type of malignant epithelial neoplasm of sinonasal tract. It represents approximately $3 \%$ of all head and neck malignancies and fewer than $1 \%$ of all malignant neoplasms. ${ }^{1,2}$

Sinonasal squamous cell carcinoma affects men more than women and is most frequent in $6^{\text {th }}$ and $7^{\text {th }}$ decade. In decreasing order of frequency, the sites of occurrence include antrum of maxillary sinus, nasal cavity, ethmoid sinus, sphenoid and frontal sinuses.

Clinical presentation includes facial asymmetry, uni or bilateral nasal obstruction, epistaxis, a tumor mass palpable or visible through nasal or oral cavity, pain, persistent purulent rhinorrhoea, non-healing ulcer and exopthalmos.

Squamous cell carcinoma composed of spindle cells occur in sinonasal tract and nasopharynx. ${ }^{1,2}$ In these anatomic sites SCSC appear as fungating, ulcerating masses as compared with polypoid or exophytic appearance in their usual upper aerodigestive tract locations. The histologic features include a malignant undifferentiated spindle cell proliferation in the presence of a differentiated squamous cell component that includes severe dysplasia, CIS or frankly invasive squamous cell carcinoma.
Key words: Spindle Cell Squamous cell carcinoma (SCSC), Squamous cell carcinoma (SCC), Immunohistochemical study.

\section{${ }^{*}$ Correspondence to:}

\section{Dr. Ankur Kumar Gupta}

Quarter no. 1, Bhagwan Mahavir Hospital,

Jawai band road, Sumerpur Pali, Rajasthan.

Article History:

Received: 27-10-2016, Revised: 12-11-2016, Accepted: 29-11-2016

\begin{tabular}{|l|c|}
\hline \multicolumn{2}{|c|}{ Access this article online } \\
\hline $\begin{array}{l}\text { Website: } \\
\text { www.ijmrp.com }\end{array}$ & Quick Response code \\
\hline DOI: & \\
10.21276/ijmrp.2016.2.6.030 & \\
\hline
\end{tabular}

\section{CASE REPORT}

A 50 years old male was presented in ENT department of our hospital with the complaint of bilateral nasal bleeding and left cervical neck swelling.

On detailed history patient had been suffering from left cervical neck swelling and bilateral nasal bleeding on \& off since last 9 months. The physical examination revealed several enlarged lymph node on both Rt. as well as left Side of the neck. On examination systemic examination normal, abdomen soft and general condition of patient was fair. Nasal examination revealed mass in both nostrils which were polypoid, reddish and bleed on touch. The patient was advised CT neck and immediately planned for FNAC of cervical swelling. A CT scan of the para-nasal sinuses was done which revealed fairly large mass involving the naso-pharynx and oropharynx, erosion of the skull base with extension into the nasal and oral cavity. Possibility of chordoma or an invasive pharyngeal malignancy was made on CT.

FNAC of the left cervical node was done which was firm in consistency, $4 \times 3 \mathrm{~cm}$ in size reveal non-keratinizing squamous cell carcinoma along with many clusters and isolated spindle cell. A diagnosis of squamous cell carcinoma- spindle cell variant was 
given and advised for punch biopsy of neck node and nasal mass. Punch biopsy of left nasal mass was performed and specimen was sent for histopathological examination.

The histopathological examination revealed normal \& ulcerated respiratory epithelium and subepithelial tissue show diffuse proliferation of large polygonal cells in sheets \& nests and in few bits with intermixed spindle cells.[Fig 1] The diagnosis was given

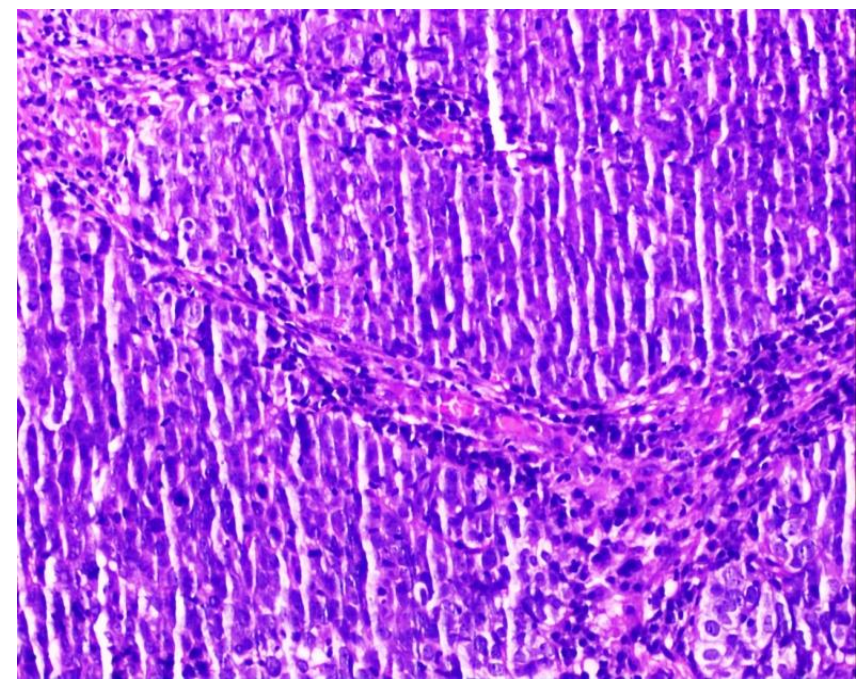

Fig 1: Section showing diffuse proliferation of large polygonal cells in sheets \& nests and in few bits with intermixed spindle cells ( $H$ and $E x 40$ ).

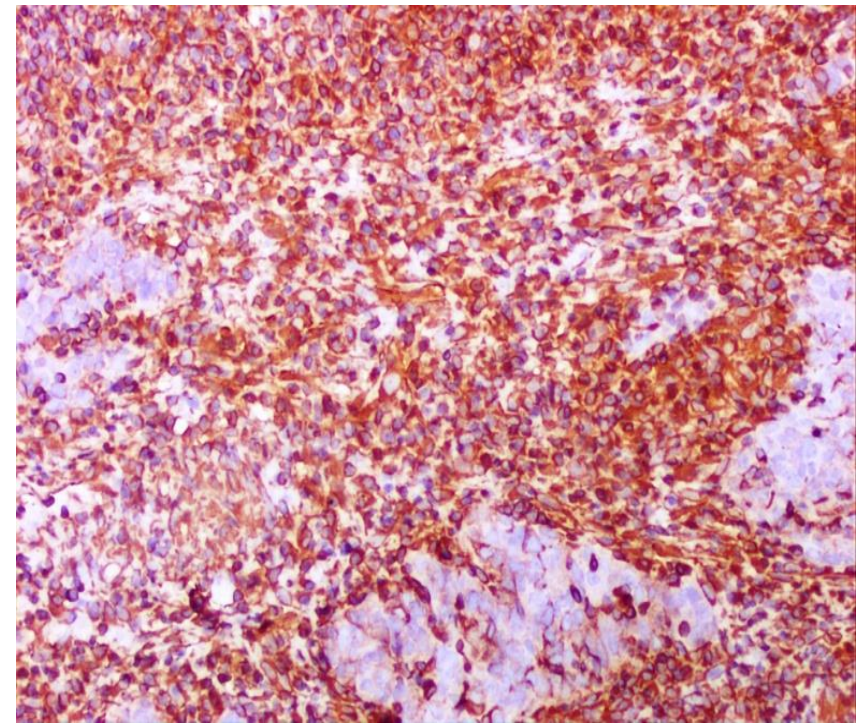

Fig 3: IHC with Vimentin showing Positivity (x 40)

\section{DISCUSSION}

Spindle cell variant of squamous cell carcinoma of sinonasal tract is a highly malignant tumor. It is a rare tumor. It occurs most often in the sixth and seventh decades and shows a strong male preponderance. ${ }^{3}$ Common primary site include antrum of maxillary sinus, nasal cavity, ethmoid sinus, sphenoid and frontal sinuses. Spindle cell variant of squamous cell carcinoma has a unique macroscopic growth pattern. Most tumors present as fungating, ulcerated, exophytic masses. ${ }^{3,4}$

In this case tumor presents as bilateral polypoid, reddish ulcerated nasal mass which were bleed on touch and left cervical mass. FNAC of cervical mass shows Spindle cell variant of squamous cell carcinoma and punch biopsy of nasal mass shows spindle cell variant of sinonasal squamous cell carcinoma. as sinonasal squamous cell carcinoma spindle cell variant. Immunohistochemistry showed tumor cells positive with pancytokeratin, Vimentin and p63,[Fig 2-4] while negative with HMB45 and S-100.

The patient was referred to a cancer hospital for the further management and was closely followed up. The patient is under treatment with radiotherapy and chemotherapy.

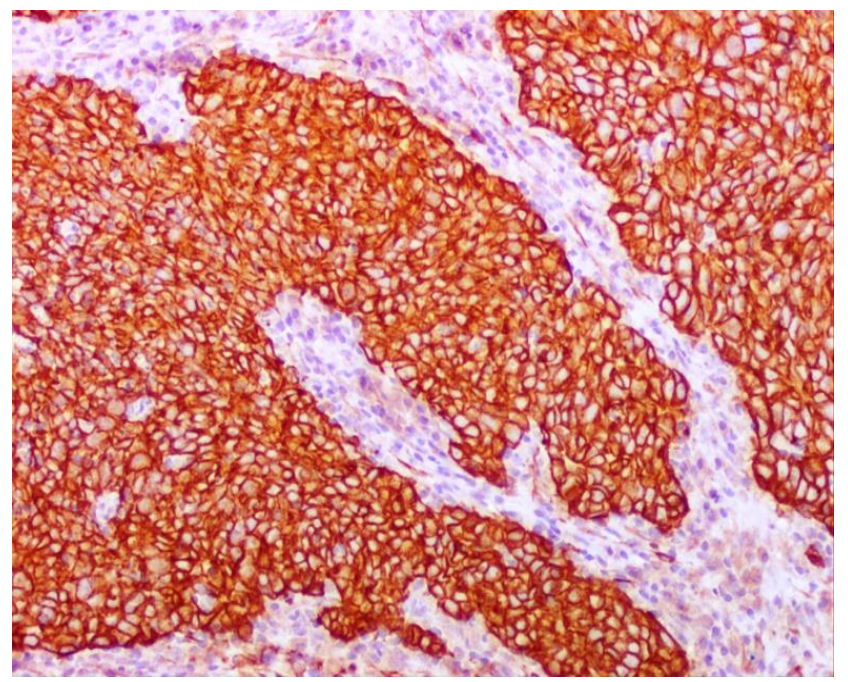

Fig 2: IHC with Pan-cytokeratin marked positivity. (x 40)

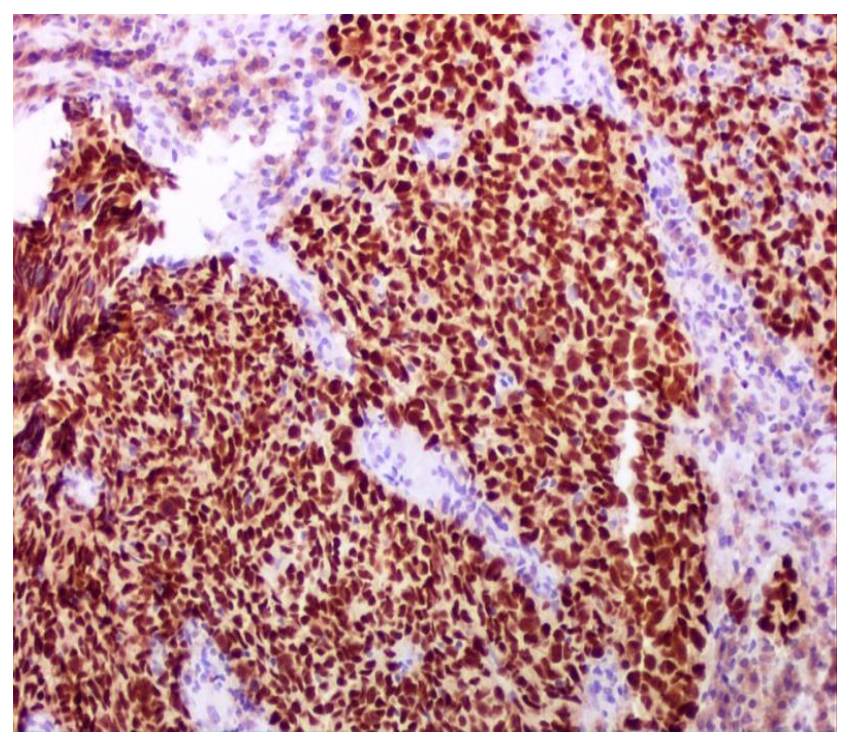

Fig 4: IHC with P63 showing Positivity (x 40)

Spindle cell carcinoma is considered to be a biphasic tumor that is composed of a squamous cell carcinoma (in situ or invasive) and spindle cell carcinoma with sarcomatous appearance. ${ }^{5} \mathrm{SpCC}$ is also considered to be a monoclonal epithelial neoplasm with the sarcomatoid component derived from squamous epithelium. ${ }^{5}$ Immunohistochemical studies may be helpful in diagnosis of SCSC. ${ }^{6-9}$ Epithelial markers include keratin (AE1/AE3, CK1, 8, 9). Mesenchymal markers include Vimentin, desmin. ${ }^{10}$ The spindle cells are keratin positive in majority of cases, but cytokeratin may be absent in app. $40 \%$ cases. Therefore, the absence of cytokeratin does not rule out diagnosis of SCSC. In these cases diagnosis of SCSC is suggested by absence of markers for other alternative diagnoses that include Mucosal malignant melanoma or other malignant mesenchymal tumors. 
The importance of diagnosing SCSC is lying in the fact that these are more aggressive than conventional SCC and are more radioresistant. Sinonasal spindle cell carcinoma specifically have worse prognosis than similar tumors in upper aero-digestive tract. In the comparison of spindle cell squamous carcinoma of various upper aero-digestive sites, Batsakis et al $(\mathrm{J})^{11}$ reported $70 \%$ mortality for sinonasal SCSC as compared with $60 \%$ for oral cavity and $30 \%$ for laryngeal SCSC. Local recurrence and metastasis are common to cervical lymph nodes and lungs. The histology of metastatic deposits may include conventional SCC alone, Spindle cell carcinoma alone or both Spindle and conventional squamous cell types. Etiological factors associated with sinonasal or nasopharyngeal SCSC are not well identified. CT scan, MRI also plays an important role in early detection and extent of primary lesion. Histopathology and immunohistochemical study of the biopsy tissue helps to reach final diagnosis before formulation of treatment plan. Recent studies have suggested that addition of chemotherapy to radiotherapy improves the treatment results. (AlSarraf et al., 1998). ${ }^{12}$

\section{CONCLUSION}

SCSC is one of the most easily misdiagnosed tumors because it does not present with nasal symptoms; rather, the patient may initially have unspecific signs \& symptoms and presented as cervical lymphadenopathy. If SCSC is suspected, a rapid pathological diagnosis and a high-dose radiation therapy with early adjuvant chemo-radiotherapy are essential to ensure prolonged patient survival.

\section{REFERENCES}

1. Bosch A, Vallecillo L, Frias Z, Cancer of nasal cavity; Cancer 37: 1458-1463.

2. Hopkin N, Minicoll W, Dalley VM et al. 1984, cancer of the paranasal sinuses and nasal cavities Part I Clinical features. J Laryngol Otol 98:585-595.

3. Batsakis JG, Rice DH, Hovard DR 1982. Th e pathology of head and neck tumors: Spindle cell lesions of upper aerodigestive tract part 14. Head Neck Surg 4: 499-513.

4. Thompson LD, Wieneke JA, Miettinen M, Heffner DK. Spindle cell (sarcomatoid) carcinomas of the larynx: a clinicopathologic study of 187 cases. Am J Surg Pathol 2002;26:153-70.

5. N. Katase, R. Tamamura, M. Gunduz et al., "A spindle cell carcinoma presenting with osseous metaplasia in the gingiva: a case report with immunohistochemical analysis," Head and Face Medicine, vol. 4, no. 1, article 28, 2008.

6. Huntington AC, Langloss JM, Hidayat HA.1990. Spindle cell carcinoma of the conjunctiva, an immunohistochemical and ultrastructural study of six cases. AM Acad Opthalmol 97:711-717. 7. Takat $T$, Ito $H$, Ogawa I et al,1991. Spindle cell squamous carcinoma of the oral cavity, An immunohistochemical and ultrastructural study of the histogenesis and differential diagnosis with a clinicopathologic analysis of 6 cases. Virchows Arch (A) Patholo anat 419: 177-182.

8. Naklesh RE, Zarbo RJ, Ewings Et al 1993. Myogenic differentiation in spindle cell carcinoma of upper aero-digestive tract. Appl Immunohistochem1:58-68.

9. Balercia G, Bhan AK, Dickersin GR,1995 Sarcomatoid carcinoma: An ultrastructural study with light microscopic and immunohistochemical correlation of 10 cases from various anatomic sites. Ultrastruc Pathol 19:249-263.

10. Lewis JE, Olsen KD, Sebo TJ. Spindle cell carcinoma of the larynx: review of 26 cases including DNA content and immunohistochemistry. Hum Pathol 1997;28:664-73.

11. Batsakis JG, Suarez P: Sarcomatoid carcinomas of the upper aerodigestive tracts. Adv Anat Pathol 2000;5:282-293.

12. Al-Sarraf $M$ et al. Chemoradiotherapy versus radiotherapy in patients with advanced nasopharyngeal cancer: phase III randomized Intergroup study 0099. 1998:223-24.

\section{Source of Support: Nil. Conflict of Interest: None Declared.}

Copyright: (c) the author(s) and publisher. IJMRP is an official publication of Ibn Sina Academy of Medieval Medicine \& Sciences, registered in 2001 under Indian Trusts Act, 1882.

This is an open access article distributed under the terms of the Creative Commons Attribution Non-commercial License, which permits unrestricted non-commercial use, distribution, and reproduction in any medium, provided the original work is properly cited.

Cite this article as: Khatri Kishore, Kumar Ankur, Sharma Mayank. Metastatic Spindle Cell Variant of Squamous Cell Carcinoma of Nasal Cavities Initially Presenting as Cervical Lymphadenopathy: A Case Report. Int J Med Res Prof. 2016; 2(6):151-53. DOI:10.21276/ijmrp.2016.2.6.030 